\title{
Comparing Mediation Role of Cultural Intelligence and Self-Efficacy on the Performance of International Business Negotiation
}

\author{
Nong Thi Hong Lam ${ }^{1}$, Shu-Yi Liaw ${ }^{2}$ \\ ${ }^{1}$ Department of Tropical Agriculture and International Cooperation, National Pingtung University of Science and \\ Technology, Taiwan \\ ${ }^{2}$ Management College, Computer Centre, National Pingtung University of Science and Technology, Taiwan \\ Correspondence: Shu-Yi Liaw, Management College, Computer Centre, National Pingtung University of Science \\ and Technology, Taiwan.
}

Received: May 13, 2017

Accepted: June 2, 2017

Online Published: June 7, 2017

doi:10.5539/ibr.v10n7p22

URL: https://doi.org/10.5539/ibr.v10n7p22

\begin{abstract}
The study examines the direct and mediating effects of personality factors of Vietnamese negotiators on international business negotiation performance. The theory is developed regarding the three elements: Quality of communication experience, cultural intelligence and negotiation self-efficacy. This study found that quality of communication experience has a strongly positive impact on the performance. Cultural intelligence and negotiation self-efficacy have strongly mediating effects on the performance. Additionally, cultural intelligence and negotiation self-efficacy have reciprocal positive effects. Overall, this study concludes that the tested personality factors have a significance effect on the performance of Vietnamese negotiators in international business negotiation. Therefore, negotiators should focus on enhancing more experience in communication, this is vital and the first priority factor which negotiators need to gain and improve. Furthermore, they have to improve their level of cultural intelligence through accumulating more cultural knowledge and behavior interaction with unfamiliar cultural backgrounds. Cultural intelligence appears to be an indispensable factor in an international context which helps negotiators to deal with cultural barrier issues effectively. Finally, negotiation self-efficacy is important to obtain a better performance which will be ameliorated along with the support of quality of communication experience and cultural intelligence.
\end{abstract}

Keywords: quality of communication experience, cultural intelligence, negotiation self-efficacy, international business negotiation performance, negotiators

\section{Introduction}

With today's global economic integration, companies are extending their frontier beyond the domestic market and accessing international markets. This irreversible trend has brought companies from many different parts of the world to do business with each other, making international business negotiation a requisite for companies. In the context of international business, negotiation is accentuated by the importance of culture and cultural differences which has significantly impact on the outcome (Angelmar \& Stern, 1978), because international business negotiation involves at least two or more parties coming from different cultural backgrounds (Liu \& Liu, 2006), it is common to observe that negotiators come from different countries with different cultural values and beliefs which they usually bring to negotiating tables. Those cultural variations can cause challenges for the involved negotiators from the first to the last stage of the negotiation. On the one hand, the cultural differences might limit the opportunities to improve the benefits for involved parties and bring conflicts and misunderstandings to the negotiating table (Liu \& Liu, 2006). Furthermore, they affirmed that cultural difference cause the intricateness and paradoxicalness for the international business negotiation table, McCall and Warrington (1989) added that the problems of conflict resolution and changing of behavior for the benefit of another has become even more complex. An explanation that, besides the complexity of conflicting interests, the negotiators have to face challenges by their own different personalities, values, attitudes, way of expressing interesting messages, a way of handling the negotiations and so forth. Moreover, it was pointed out by Ghauri (1983) that the main reason for the complex is that many eventful issues have to be managed by negotiators that primarily do not know each other very well, notably who have different cultural backgrounds. Hence, the negotiators play a paramount importance role, they are the decisive factors in the success of the negotiation. 
Particularly, the personality factors of the negotiators have profound effects on their performance, because they will influence the negotiation performance by their own experiences, confidence and skills in intercultural context (Ghauri \& Usunier, 2003).

Increased awareness of the personality factors which has significantly impacted on negotiators' performance in international business negotiation context allows negotiators to develop and improve their strengths and capabilities, predispose negotiators for successful performance and work globally in the intercultural context. Furthermore, awareness of personality factors reveals as to what characteristics of negotiators can be selected and trained upon in order to maximize the chances of reaching the optimal agreements in negotiation that traverse cultural borders. In this paper, three personal elements are explored: Quality of communication experience, cultural intelligence and negotiation self-efficacy, moreover, their reciprocal relationship is also examined.

There has been a growth in researches focused on international negotiation in recent years and there are many books written to guide negotiators around the world on "how to negotiate with..." which attempt to provide universal tactics regarding negotiation. "To step into another culture needs knowledge about that culture, but evens more it needs ability to think and feel from that cultural perspective" (Wenzlaff, 2008). There is still a gap in the literature regarding on negotiators' characteristics, especially how quality of communication experience impacts on international business negotiation performance with the mediation effects of cultural intelligence and negotiation self-efficacy. Furthermore, existing research on negotiation mostly focus on developed countries, there are exhaustive studies on personal negotiators and international business negotiation for developing countries, especially Vietnam. Therefore, this study addressed the gap in terms of figuring out the profile of Vietnamese negotiators and how the differences in their profile impacts on their performance in international negotiation, investigating on how quality of communication experience, cultural intelligence and negotiation self-efficacy effects on negotiators' performance as well as their mutually effect relationship at a point. A convergence of three personality factors has been set up in a series multiple mediation model which have not been developed in the previous research.

\section{Literature Review}

\subsection{International Business Negotiation Performance}

International business negotiation is "unique", fundamentally falling into two categories: Stage models of the negotiation process and behavior motivated by cultural concerns (Fayerweather and Kapoor's, 1976), and broad international frameworks or schemata. The process model for all cultures keys on the purpose and nature of negotiators' successive interaction (Graham, 1987), which includes four phases of non-task sounding; task related information exchange, persuasion, and concession and agreement. For the broad international frameworks, Fayerweather and Kapoor (1976) underscore the "wide variety of environments" in international business. This framework includes: the negotiation situation, functional areas, four Cs (common interests, conflicting interests, compromise, and criteria for undertaking negotiation), the environment (political, economic, social and cultural system) and the perspective (that is the broad factors like the previous negotiation experiences which influence the negotiation at hand). A conceptual paradigm of international business negotiation have been set by Tung (1988), hence the paradigm comprises of the negotiation context, negotiators' characteristics, strategic selections and process, and the negotiation outcome. Eventually, McCall and Warrington (1989) has studied and described the international or intercultural business negotiations from an interaction perspective as they offer the notion that the whole conceptual base of problem-solving, conflict resolution, change agent and decision-making skills within the international business interaction should be considered through the negotiation function. By using the idea of negotiation and the interpersonal interaction, it is feasible to conceptualize the output of marketing planning in the international markets in terms of mutual agreements that have to be negotiated. Finally, a theoretical contribution of various domains such as social psychology, social anthropology, sociology, political science and business administration can be traced. Those different disciplines have been developed in order to describe a negotiating model. The model can be explained as follows: International business negotiation is a complexity task, then in this situation each evolved parties always hope about a success negotiation, that is negotiation outcome. A negotiation outcome is the result of the interaction with the partners (Thompson, 1990). Usunier (1996) identified five outcome orientations that vary among different cultures, these include partnership, contract, profit, winning and the time expectations of the negotiation, and the outcome is evaluated by negotiation performance, usually based on a continuum of success to failure.

\subsection{The Quality of Communication Experience Impacts on the International Business Negotiations Performance}

In the context of international negotiation, the ability to communicate effectively across culture is critical. All of 
the information sharing, emotional expressing or conflicts dealing will be tackled by communication process. Liu et al. (2010) has proposed an important personality factor which influences negotiation that is quality of communication experience (QCE). QCE is defined as a multi-dimensional construct which consists of three elements: clarity, responsiveness, and comfort that the individual experiences during social interaction. First, clarity is the level of understanding of the meaning being communicated and will reflect on the cognitive aspect of the communication experience. Second, responsiveness refers to the behavioral aspect of the communication experience and it indicates the norm of coordination and reciprocity of an individual experiencing an interpersonal interaction. They further explained that the coordination and reciprocity present the synchronization of speech pattern, respond to the inquiring of information and explicit empathy to the other parties' emotions. Therefore, responsiveness in interaction is essential for all sides at the negotiating table to avoid unfulfilled expectations as well as conflicts among negotiators' communication. Thirdly, comfort is the condition of positive affect of ease and pleasantness when interacting with each other. Therefore the comfort experienced by communicators reflects the affective aspect of communication. QCE construct is particularly salient and it plays a significant role in intercultural interaction, international business negotiation is in there (Liu et al., 2010). In that, the high degree of clarity that negotiators interpret through the information exchange leads to better economic outcomes (Adair et al, 2004; Pruitt, 1981). Adair et al. (2001) explained that with a high le vel of clarity, negotiators will be more understanding about the other parties' position, interests, preferences, priorities, resources and capabilities. These help negotiators to find out the optimal option, set up the general ground with other parties, coming up with an integrative solution which achieves their economic outcome. The research of Weingart et al. (1990) and Weingart et al. (1993) have indicated that when negotiators are responsive to each other, they are more likely to achieve better economic outcomes and be more satisfied with the negotiation. Furthermore, with responsiveness to each other, the trust is built through the cooperation among parties would enhance their satisfaction with the negotiation. Finally, Adair et al. (2004) also pointed out that high comfort level to be experienced during negotiation influences the economic gain. With comfort, the comfortable atmosphere surrounding the negotiation is created, giving the negotiators more motivation to carry out their task. Consequently, with a high level of QCE, negotiators will achieve better performance in international business negotiation.

Hypothesis $\left(H_{1}\right)$ : Quality of communication experience has a positive impact on the international business negotiations performance.

\subsection{The Mediating Role of Cultural Intelligence}

Cultural intelligence (CQ) is an individual's capacity to function and manage effectively in culturally diverse settings (Early \& Ang, 2003). This concept has become an important orientation in the context of global organizations with increasingly diverse workforce as well as work settings.

Ang and Dyne (2008) have proposed CQ as a mediator of the relationship between distal individual characteristic (such as personality traits, worldviews, demographic and biographical differences) and intercultural effectiveness. A list of research which prove CQ as a strong mediator in intercultural performance are: Ward and Fischer (2008) whose about international exchange students in New Zealand has shown that CQ is mediator between personality traits (cultural empathy, open-mindedness) and flexible general adjustment. Dyne et al. (2008) who indicated that CQ mediates the effects of international experience on international leadership potential of cultural diverse participants of an executive development program (Ang et al., 2015). In this study, we apply mediator CQ and propose that it has a mediation effect between QCE and performance of international business negotiation. CQ is learning capability through cross cultural interactions (Nguyen et al., 2009), so from repeated international negotiation and experience in cross cultural interaction, negotiators gain more and more knowledge of culture and they know how to interact appropriately in unfamiliar cultures. Therefore, we propose the hypothesis as following:

Hypothesis $\left(\mathrm{H}_{2}\right)$ : Cultural intelligence is a mediator of the relationship between quality of communication experience and international business negotiation performance.

\subsection{The Mediating Role of Negotiation Self-efficacy}

Negotiation self-efficacy (NS) is developed by O'Connor and Arnold (2001) as it refers to one's confidence in his or her ability to perform successfully in the task of negotiation. This concept has become one of the most important factors in negotiation. It is especially essential for negotiators to drive the negotiation to a success. Locke et al. (1984) have pointed out that individuals with low self-efficacy choose lower goals, meanwhile goals level definitely influence the negotiation performance (Huber \& Neale, 1987). And the evidence has indicated that low self-efficacy individuals tend to have less persistence when they encounter set-backs and easily to give 
up or stop their efforts prematurely (Miles \& Maurer, 2012). Those behaviors are highly essentials for negotiation. Liu et al. (2010) has found that QCE has positively impact on NS. In the context of international business negotiation, negotiators are very easy to be nervous, frustrated or unable to interpret the information as well as lost their ability to express their preferences or priorities to other parties. This can cause anxiety and uncertainty for negotiators. Stephan and Stephan (1995) had pointed out that anxiety causes the feeling uneasy or apprehensive about what might happen, in that uncertainty entails the inability to interpret, predict or explain the other side's feelings, attitudes and behavior (Berger \& Calabrese, 1975). This directly impact the communication experience (Gudykunst, 1995). Eventually, when the anxiety is high, people tend to fall back to simplistic information processing such as stereotypes, and the high uncertainty makes people not confident enough to dealing with other side's expressions in term of feelings, attitudes, and behavior. This makes negotiators less confident about themselves. Then, with high uncertainty and anxiety in international negotiation, negotiators may drive the communication to a failure because of misinterpretation and misunderstanding. Adair et al. (2001) also stated that negotiators, who had experienced the intercultural interaction, will be more confident especially when their degree of clarity is high, and the comfort appears among the parties. Hence, their confident is increased, and as O'Connor and Anold (2001) have found out that with a high level of NS, negotiators are able to perform the negotiation task better and gain successful performance. A hypothesis is as follo wing:

Hypothesis $\left(H_{3}\right)$ : Negotiation self-efficacy is a mediator of the relationship between quality of communication experience and international business negotiation performance.

Earley (2002) argued that individuals have a high level of cultural intelligence will be more confident of their knowledge and capabilities to dealing with cultural barriers smoothly as well as perform their negotiation task with their international encounters successfully. CQ has appeared to become an efficient mediator (Ang et al., 2015). As the theories indicates that CQ has mediation effects between inborn basic processes such as personality, cognitive ability and a number of dimensions performance (Oolders et al., 2008). CQ is proposed to have an influence on NS of a negotiator and it can lead to a better performance. Because, with sufficient knowledge about other parties' cultural and the system of culturally specific, negotiators can adapt to the unfamiliar cultural backgrounds intimately and effectively. This creates a better feeling for negotiators during the interaction, and it makes negotiators more confident to perform the reactions and behaviors well which satisfied other parties.

Furthermore, based on the above discussion, we have indicated that QCE of negotiators experiencing during the previous negotiation will increase the level of $\mathrm{CQ}$ of negotiators. Because through repetition times of participating in international business negotiation, negotiators will gain more knowledge about culture, furthermore, they feel more comfort with the negotiation and especially they are very clear about the expressing appropriate behaviors to adapt effectively to parties' culture. This creates a friendly negotiation atmosphere and leads to a better performance of negotiators. Briefly, a high level of QCE will drag up the level of CQ, then increases the level of NS and finally leads to a high performance. This study proposes hypothesis $\mathrm{H}_{4}$ below:

Hypothesis $\left(\mathrm{H}_{4}\right)$ : Cultural intelligence has a positive impact on negotiation self-efficacy, which leads to greater performance of international business negotiation.

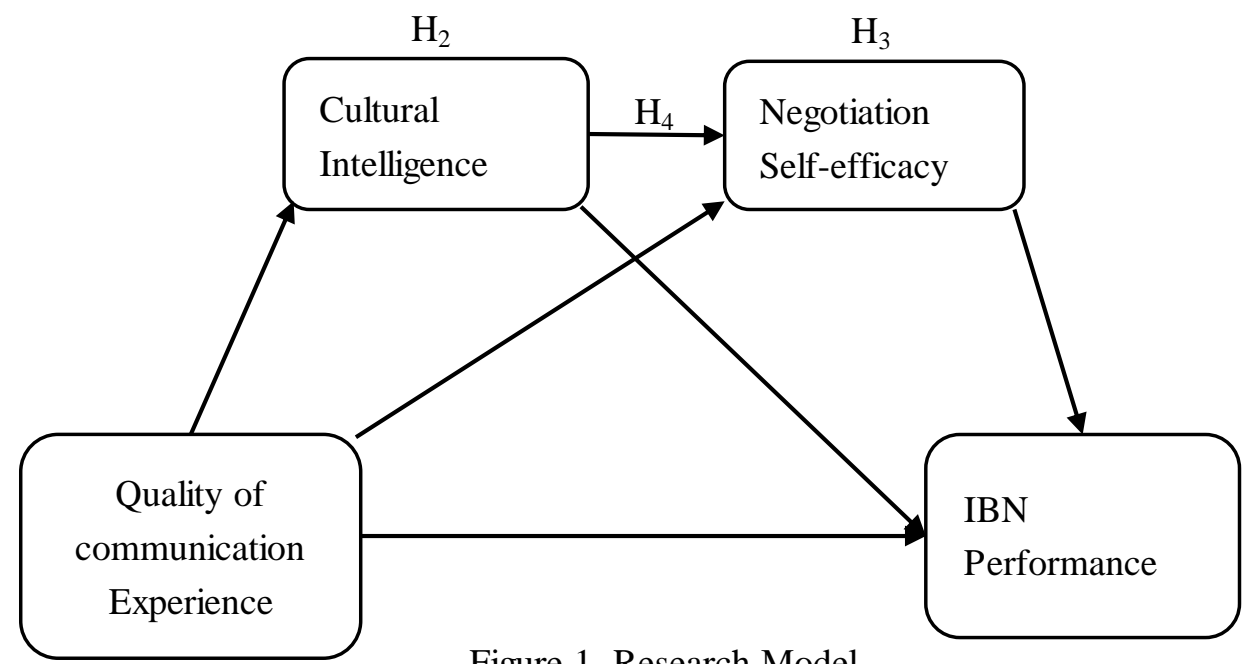

Figure 1. Research Model 


\section{Methodology}

This study was designed as an experimental research which applies questionnaires as an instrument to collect data from 188 respondents in the two important areas in Vietnam - The key economic Zone North and South in Vietnam. The collected data were analyzed by descriptive, one-way ANOVA and path analysis methods. The Sobel test is an approximate significance test for the indirect effect, involving the computed ratio of path coefficient of mediation path to its estimated standard error (Preacher and Hayes, 2008). SPSS and AMOS version 22 were used for analysis procedure.

\subsection{Measurement}

There are four variables in the study. First, performance of international business negotiation is the dependent variable in the model. The performance in negotiation refers to the outcome of the negotiation in terms of partnership, profit, contract, winning and time orientation which vary among cultural differences, usually based on a continuum of success to failure (Usunier, 1996). The performance in negotiation is important and is influenced by various factors. In this study, the performance of international business negotiation is used as a measure of negotiators' personal performance the negotiating in an international context through three factors: quality of communication experience, cultural intelligence and negotiation self-efficacy. Second, quality of communication experience is the independent variable in the model which is a vital element for the negotiator in dealing with the exchange information, preferences, priorities, emotions, conflicts and attitudes during the negotiation. QCE tests the clarity, responsiveness and comfort of negotiators during the international negotiation process. Third, cultural intelligence is played as a mediator in the model of this study. CQ measures the cognitive, behavioral and motivational of negotiators in the intercultural context. Specifically, how one understands other parties' culture, how one can manage and adapt effectively to the diverse cultural situation. Finally, negotiation self-efficacy refers to the confidence of an individual in doing the negotiation task is a needed and essential factor of any negotiator. NS plays as a mediator in the model; it tests the level of confidence of the negotiator in doing the task of negotiation in the international context.

\subsection{Questionnaire Design}

This study used closed-ended questionnaires with multiple choice questions. The questionnaire consists of two sections: section 1 - Respondents' personal information and section 2 - main questions. Section one: Including 6 items about the detailed information of the respondent's profile such as gender, age, current position, living region, and type of industry and the time of taking part in international business negotiation. Section two: The main content pertains to negotiators characteristics which are divided into four sections that are: Negotiation self-efficacy consists of 5 items, quality of communication experience involves 6 items, cultural intelligence includes 16 items and international business negotiation performance comprises 9 items, overall 36 items. Those items was measured by $7-$ point Likert scale $(1=$ strongly disagree, $7=$ strongly agree $)$ with higher score indicating the higher level of NS, QCE, CQ and performance. (Detailed measurement is shown in appendix).

\subsection{Respondents}

The study was conducted in Vietnam and focusing on two key economic zones: First, the key economic zone in North Vietnam, this zone involves the provinces of Northern Delta and Northeast regions. Second, the key economic zones in South Vietnam, it is also known as Southeast region (ASEAN, 2012). These two key economic regions are the dynamic economic centers and importance economic engines of this country. Similar to many other Asia countries, Vietnam's culture is high context culture, so one of the features of this context culture is that Vietnamese people pay attention in determining social status (Brett et al., 1998). Then people from this cultural tend to send a high social status as a representative to take part in an important event, especially international business negotiation. Therefore, the target sample of this study is in a high social status.

As this study applied the path analysis, so the sample size in this study was based on the research of Kline (2005) which has guided that a desirable goal is to have the ratio of the number of cases to the number of free parameters be $20: 1$ or a 10:1 ratio. This study requires minimum 140 respondents. The questionnaire was delivered to respondents by email, through companies and directly contact to the respondents. Twelve invalid responses were deleted and the data was analyzed with a total of 176 responses ( 88 responses in North and South individually).

\section{Results and Discussion}

Cronbach's $\alpha$ values were calculated to test the internal consistency of the indicators above 0.9 which are higher than recommended value 0.70 (Hair, 2010). Therefore, all constructs were internally consistent and reliability. 


\subsection{Descriptive Analysis}

Generally, most of the Vietnamese negotiators are young (under 30 years old), the majority of them are working in the field of higher education (34.1\%). Regarding their experience in international business negotiation, the result showed that Vietnamese negotiators are still less of experienced, the statistic indicated that most of them had from 1 to 3 times negotiating with Eastern and Western parties. It can be explained that because most Vietnamese negotiators in this study are of a young age, they have just embarked on their career.

\subsection{Respondents' Profile Impacts on Performance of International Business Negotiation}

An overview of the impact of respondents' profile on international business negotiation performance has been presented in Table 1. Gender and living area between North or South of Vietnamese negotiators do not have any significance effect on their performance in international business negotiation. Meanwhile, their age and their time of participating in negotiation play a strong impact on their performance. Specifically, the more senior they are, the better performance they achieve, in this study, we found that group of 41-60 years old did the best in international business negotiation $(M=6.02)$. Next, the more experiences they had, the better performance they attain. This is easy to understand when they have experienced, they are more clearly about what they need to do, how to respond, how to perform effectively.

Table 1. Variance of Respondents' Profile to Performance

\begin{tabular}{|c|c|c|c|c|c|c|}
\hline Variables & & $\mathrm{M}$ & SD & $\mathrm{F}$ & $\mathrm{p}$ & Post Hoc tests \\
\hline \multirow{2}{*}{ Gender } & (1) Female & 5.79 & 0.98 & \multirow{2}{*}{0.88} & \multirow{2}{*}{0.35} & \multirow{7}{*}{$(1)<(2,3)$} \\
\hline & (2) Male & 5.72 & 0.97 & & & \\
\hline \multirow{3}{*}{ Ages } & (1) Under 30 & 5.27 & 1.05 & \multirow{3}{*}{12.98} & \multirow{3}{*}{$0.00 *$} & \\
\hline & (2) $31-40$ & 5.94 & 0.78 & & & \\
\hline & (3) $41-60$ & 6.02 & 0.76 & & & \\
\hline \multirow{2}{*}{ Areas } & (1) North & 5.69 & 1.02 & \multirow{3}{*}{0.59} & \multirow{3}{*}{0.45} & \\
\hline & (2) South & 5.59 & 0.93 & & & \\
\hline \multirow{3}{*}{ Times } & (1) $1-3$ times & 5.31 & 1.02 & & & \multirow{3}{*}{$(1)<(2,3)$} \\
\hline & (2) $4-7$ times & 5.91 & 0.87 & \multirow[t]{2}{*}{11.18} & \multirow[t]{2}{*}{$0.00 *$} & \\
\hline & (3) More than 8 times & 6.06 & 0.66 & & & \\
\hline
\end{tabular}

Note: $* p<0.05$

This finding indicates that along with Vietnamese negotiators' seniority, they gained more experiences in work as well as full knowledge and professional capability which can help them in dealing with counterparts. Furthermore, their experiences in coordination with other parties combine with their skills have a strongly positive effect when they come to an international business negotiation. Additionally, with more international experiences (more than 8 times) negotiators have the ability to translate their multicultural skills into knowledge in order to be more effective in the outcome. Therefore they definitely achieve great performance.

\subsection{Path Analysis}

An overview of correlations between independent variables is provided in Table 2. Generally, the correlations among variables are moderately positive $(r>0.6)$ (Gerber \& Kristin, 2005). This result indicated that with moderately correlation relationship among the variables, those variables are good to continue for hypotheses analysis.

Table 2. Correlation Matrix

\begin{tabular}{lccc}
\hline & NS & QCE & CQ \\
\hline Negotiation Self-efficacy (NS) & 1 & & \\
Quality of Communication Experience (QCE) & $0.786^{* *}$ & 1 & 1 \\
Cultural Intelligence (CQ) & $0.675^{* *}$ & $0.661^{* *}$ & 1 \\
Overall Performance (P) & $0.665^{* *}$ & $0.683^{* *}$ & $0.708^{* *}$ \\
\hline
\end{tabular}

Note: $* p<0.05, * * p<0.01, * * * p<0.001$

\subsubsection{The Direct Effect of Quality of Communication Experience on Performance}

In the initial hypothesis, this proposed that quality of communication experience has strongly positive impact on the performance of negotiators in international business negotiation. Figure 2 showed that QCE has total effect on performance ( $\mathrm{c}=0.65, \mathrm{t}=12.35^{* * *}$ ), when adding the mediators (Figure 3), QCE decreases its effect on performance $\left(\mathrm{c}^{\prime}=0.28, \mathrm{t}=3.43^{* * *}\right)$, but it still maintains the positively and significantly impacts on international business negotiation performance, so hypothesis $\mathrm{H}_{1}$ is supported by this research. 


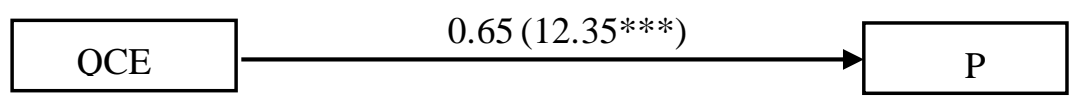

Figure 2. The result of direct effect

The QCE is a very important factor for negotiators in determining the success in the intercultural negotiation context. So, it suggests that negotiators should gain more experience and skill in communication, as it is emphasized by Lewicki, Minton and Saunders (2000) that "communication is the heart of negotiation" which has expressed the role of good communication in the negotiation context. Because, communication is the essential tool for sharing the information, expressing the priorities and preferences, showing the emotional and attitudes, and resolving the conflict during the negotiation. Therefore, improving the communication experience is essential and enhances a good quality in communication experience through enriching the cognitive knowledge to be more clarify, express the responsibility and maintain the comforting environment in international negotiation is very necessary for each of negotiator.

\subsubsection{Multiple Mediation of Cultural Intelligence and Negotiation Self-efficacy}

The results are mixed with regard to the indirect effects of cultural intelligence and negotiation self-efficacy on the performance.

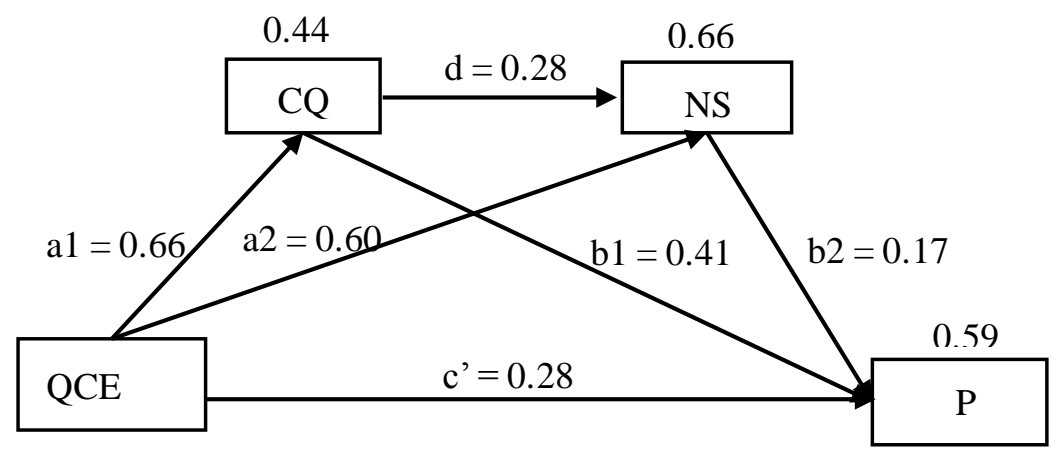

Figure 3. The results of mediation model

Table 3. Sobel Test of Indirect Effects

\begin{tabular}{llllll}
\hline Path & Coefficient & Se & Coefficient & Se & Sobel - z \\
\hline QCE $\rightarrow$ CQ $\rightarrow$ P (Ind1) & $0.66\left(\mathrm{a}_{1}\right)$ & $0.05\left(\mathrm{Sea}_{1}\right)$ & $0.41\left(\mathrm{~b}_{1}\right)$ & $0.74\left(\mathrm{Sea}_{2}\right)$ & $5.29^{* *}$ \\
$\mathrm{QCE} \rightarrow \mathrm{NS} \rightarrow \mathrm{P}($ Ind2) & $0.60\left(\mathrm{a}_{2}\right)$ & $0.07\left(\mathrm{Sea}_{2}\right)$ & $0.17\left(\mathrm{~b}_{2}\right)$ & $0.07\left(\mathrm{Se}\left(\mathrm{b}_{2}\right)\right.$ & $2.01^{*}$ \\
\hline
\end{tabular}

Note: $* p<0.05, * * p<0.01, * * * p<0.001$

The Sobel test was done to assure that CQ has mediation effects in the model, the result yielded as $\mathrm{z}=5.29^{* *}$, indicated that $\mathrm{H}_{2}$ was supported. It also can be seen in the Figure 3 that $\mathrm{CQ}$ has $\mathrm{R}^{2}=0.44$. It means CQ has influence with strength prediction of the overall the model is $44.0 \%$. This result implies that the great performance can be achieved through a high level of cultural intelligence. To meet the negotiation expectations and becoming effective negotiators in global context, each individual must be enrich the cross-cultural competencies. Vietnam as a high-context culture background, it hard for Vietnamese negotiators to respond effectively to parties that come from the low-context cultural background if they do not have sufficiently knowledge and practice for the reaction. Therefore, in the international negotiation context, not only understanding about other cultures, but the negotiators also needs to be able to act in accordance with that culture. It suggests that gaining knowledge about culture and getting familiar with other cultures in order to respond appropriately are of paramount importance for international negotiators. And then, a high level of cultural intelligence will help negotiators to deal with the aforementioned problems effectively and bringing the good impression and satisfaction for their counterparts.

Regarding $\mathrm{H}_{3}$, the Sobel test was also obtained which produced $\mathrm{z}=2.01^{*}$, indicated that $\mathrm{H}_{3}$ was supported. Additionally, NS has $\mathrm{R}^{2}=0.66$ (Figure 3). This means that NS has influence with strength prediction of the overall the model is $66.0 \%$. NS has not been examined as a mediator in the previous research. Therefore, this study has found out a new mediator which has mediation effect in intercultural context. The finding means that the performance of negotiators can be improved through the high level of negotiation self-efficacy.

The path $\mathrm{QCE} \rightarrow \mathrm{CQ} \rightarrow \mathrm{NS} \rightarrow \mathrm{P}$ are significant, hypothesis $\mathrm{H}_{4}$ was supported. This result illustrates a good 
relationship between QCE and performance of international business negotiation through the two mediators CQ and NS. With a high QCE, the level of CQ of negotiators will be increased positively and then CQ will intensify the level of NS, and finally, the great performance will be made. This finding also suggests that, along with a good QCE which a negotiator has gained, they should enrich their CQ and practice their Self-efficacy in Negotiation. The higher cultural intelligence and negotiation self-efficacy, the greater performance will be achieved. And then, for the final dependent construct performance has $\mathrm{R}^{2}$ values of 0.59 (Figure 3). It indicates that the mediating variables (CQ and NS) have influence with strength prediction of the overall the model is $59.0 \%$, meanwhile $41.0 \%$ (Vietnamese negotiators) influenced by other factors or variables which not available in the model such as language ability, personality skills and working experiences.

\subsubsection{The Comparison of Indirect Effects}

Table 4. Paths Comparison of Indirect Effects

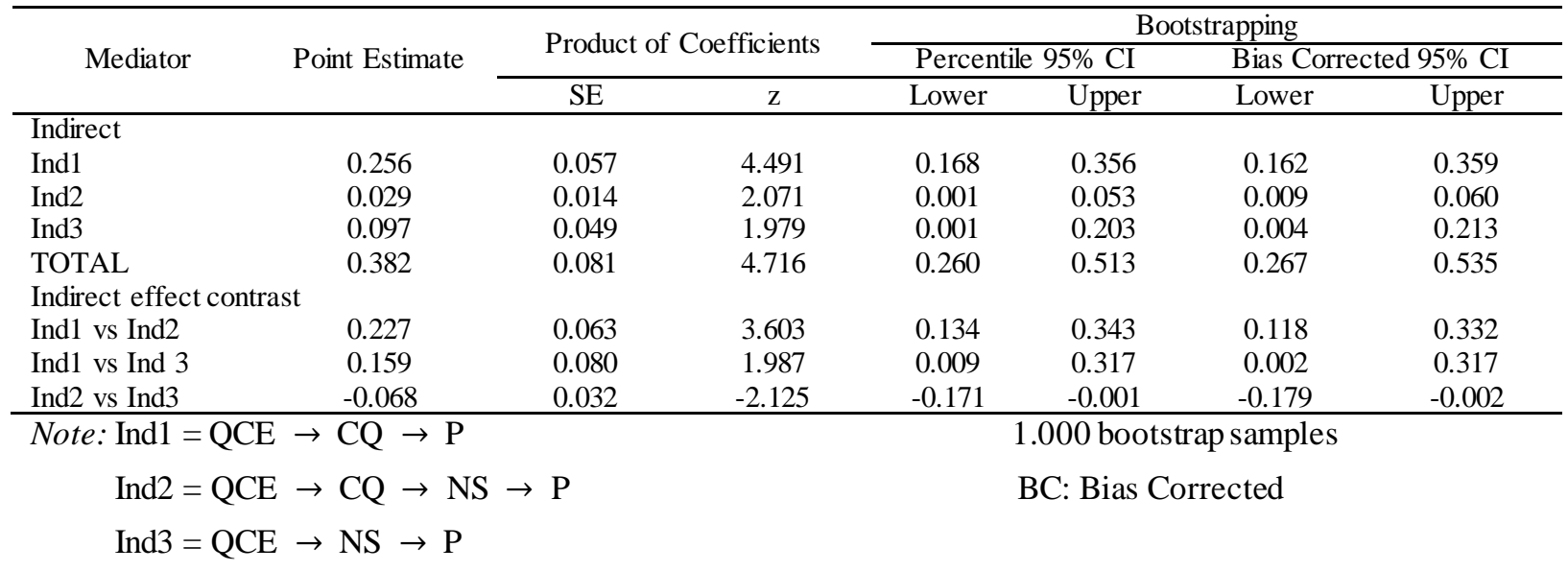

Briefly, all of the indirect effect of communication experience and performance through cultural intelligence and negotiation self-efficacy as well as through two mediators simultaneously are significant because no zero is contained in the intervals in percentile 95\% CI or Bias Corrected 95\% CI method. To see the difference among indirect effects, we look at "indirect effect contrast" in the Table 4. Based on the result of Ind1 vs Ind2, we can claim that Ind 1 do the stronger mediation effect of quality of communication experience on performance than ind2 (of 0.134 to 0.343 , BC 95\% CI of 0.118 to 0.332). Second, between Ind1 and Ind3, the result from Percentile $95 \%$ CI shows 0.009 to 0.317 and $\mathrm{BC} 95 \% \mathrm{CI}$ is 0.002 to 0.317 which means that Ind 1 has greater mediation effect than Ind3. Third, the comparison of the pair Ind2 and Ind3 yields as: Percentile 95\% CI is -0.171 to -0.001 and $\mathrm{BC} 95 \% \mathrm{CI}$ is -0.179 to -0.002 , it reflects that Ind2 has weaker mediation effect than Ind3. Finally, we have the comparison of the three indirect effects as: Ind1 > Ind3 > Ind2. This result indicates that: Firstly, cultural intelligence plays an important and strongest mediation effect on the relationship of quality of communication experience and performance. In the international context, high level of cultural intelligence appears as very important factor for each individual, therefore improve and enhance rich knowledge about culture of other countries are extremely essential. High level of cultural intelligence helps negotiators understand the norms, values, behaviors, habits and customs and translate that knowledge into appropriate attitude and respond which might satisfy and impressive partner. Secondly, when negotiators process a high level of cultural intelligence, their negotiation self-efficacy will be dragged up. Then negotiators will have a good performance when they have high level of cultural intelligence and negotiation self-efficacy at the same time to support for them. Finally, international negotiators need to improve their negotiation self-efficacy.

\section{Conclusions}

This study investigated the impact of QCE on performance of international business negotiation with two mediators: CQ and NS of Vietnamese negotiators. The finding found that majority of Vietnamese negotiators are young and their experience in international negotiation are less. Therefore, they still need to improve their specialty, knowledge and gain more experience from practical. Quality of communication experience has a direct impact on the performance. With a high level of QCE, the negotiators will obtain greater performance in international business negotiation.

CQ and NS have the significant mediating role on the relationship between QCE and negotiation performance. The performance can be achieved greater, more successful and satisfying through a high level of CQ and NS. In addition, with a higher level of CQ, NS is also being increased. This study recommends that negotiators should 
pay attention, improve and gain a high level of QCE, CQ and NS in order to attain satisfying and successful performance in performance of international business negotiation. In the previous researches, cultural intelligence has been explored to be a mediator in international interaction, howe ver negotiation self-efficacy has not been examined before, therefore in this study negotiation self-efficacy has been proved to be a mediator in this line. This finding will fulfill this gap and contribute for the negotiation literature in term of negotiators' characteristic. The negotiators always play a paramount important role in the success of the negotiation. Indeed, as of yet, culture and negotiation literature has revealed as to what characteristics of negotiators can be selected or trained upon in order to maximize the chances of reaching the optimal agreements in negotiation that traverse cultural borders. Therefore, taking an insightful look into the characteristics of negotiators has significance in selecting and training potential negotiators. Furthermore, it helps negotiators to be aware of the weakness as well as strengthens so as to adjusting and improving their ability in cross cultural context. As it is pointed out that the performance of negotiation in international context depends on the competence of negotiators. Vietnamese negotiators are expected to strengthen their personal competence in cross-cultural communication, knowledge, behaviors and self-efficacy to be more effective and professional in executing the negotiation task successful.

Culture intelligence is the strongest vital mediator on the relationship between communication experience quality and performance. Following the mediation effect of cultural intelligence, promoting their negotiation self-efficacy and then lead to high business negotiation performance. Finally, the mediating role of negotiation self-efficacy is less significant effect among others two indirect effects. Therefore, with sufficiently negotiation self-efficacy, negotiators will be more calm, comfortable and confident to share information, express priorities and preferences, handle problems during the negotiation, so that negotiators will perform their task satisfactory and successfully. In the previous researches, quality of communication experience, cultural intelligence and negotiation self-efficacy have been examined independently. Howe ver in this study, a convergence of these three personality elements in one model has been done. This study has found a close and reciprocal relationship among these factors which has provided a new model in international negotiation field.

This study has provided a useful reference for international negotiator, especially Vietnamese in terms of exploring the personality factors: quality of communication experience, cultural intelligence and negotiation self-efficacy to their performance which have not been examined in the previous academic researches. Basing on the finding of this study, Vietnamese negotiators should improve their quality of communication experience, which has come as the first factors for each individual. With high le vel of QCE, negotiator will be more clarity with the communicated information, respond at the accurately time and create a good atmosphere for the negotiation. Negotiators can improve their QCE in their working place from the real seminar, meeting or working with their customers. Through many discussions from the real situations, negotiators can enhance more skills in communication, then they also can improve the quality of the communication as well, they are master in exchange the information, respond to information in effectively and indeed way, furthermore they will be more comfortable to create a good communication environment. Second, enhance their level of cultural intelligence and negotiation self-efficacy which is a dispensable factor for negotiators to do the task in intercultural, international and global context. Negotiators can improve their level of cultural intelligence in various ways. They should learn about the knowledge of culture of many others countries through media channels such as internet, newspapers and books. Accumulating the knowledge of culture initiatively will help negotiators be more confident in performing and interacting. Moreover, learning cultural knowledge from experiences and surrounding environment are very perfect way for negotiators, then they can practice their respond to the unfamiliar culture. Additionally, negotiators should understand their parties before they come to the negotiation as where the party comes from, which cultural background they are, and so then negotiators can have a good preparation. People tend to be more confident about the thing they are master, so that with a good knowledge about culture negotiators will be more confident in performing in international context, the best performance will be done and least to a satisfaction and success at the end of the negotiation.

However, there are some limitations and suggestions can be obtained from this study. Firstly, this study has focused on examining three personality factors for Vietnamese negotiators, however apart from quality of communication experience, cultural intelligence and negotiation self-efficacy in this study, there might be still have other personality factors such as: languages ability, which impact on every single negotiators. Therefore, future researches are hoped to exploring more personality factors for Vietnamese negotiators, so that they can take seriously consideration to develop and accomplish them in order to achieve more great performance in the upcoming international business negotiations. Secondly, this study has collected the sample from two most important regions in Vietnam where the business negotiation happens regularly, however the quantity of respondents was somehow limited, especially the subject in the age from 30 to 50 years old, along with the 
subject who had more than 8 times of participating in international business negotiation were less of number due to the difficulties in approaching them. Future research is suggested to try to get more respondents with those subjects in order to show more result about the characteristic and other important factors affecting performance of international business negotiation.

\section{References}

Adair, W. L., Brett, J. M., Lempereur, A., Okumura, T., Shikhirev, P., Tinsley, C. H., \& Lytle, A. L. (2004). Culture and negotiation strategy. Negotiation Journal, 20, 87-100. https://doi.org/10.1111/j.1571-9979.2004.00008.x

Adair, W. L., Okumura, T., \& Brett, J. M. (2001). Negotiation behavior when cultures collide: The U.S and Japan. Journal of Applied Psychology, 86, 371-385. https://doi.org/10.1037/0021-9010.86.3.371

Ang, S., \& Dyne, V. L. (2008). Handbook of cultural Intelligence: Theory, Measurement and Application. Antecedents of Four-Factor Model of Cultural Intelligence. Lon Don and New York: Routledge.

Ang, S., Dyne, L. V., \& Tockstuhl, T. (2015). Cultural Intelligence: Origins, Conceptualization, Evolution and Methodological Diversity. In M. J. Gelfand, C. Y. Chiu, and Y. Y. Hong (eds), Handbook of Advances in Culture Psychology: Oxford University Press.

Angelmar, R., \& Stern, L. W. (1978). Development of a Content Analytic System for Analysis of Bargaining Communication in Marketing. Journal of Marketing Research, 15, 93-102. https://doi.org/10.2307/3150404

ASEAN. (2012). Overview. Association of Southeast Asian Nation. Retrieved 18 December 2015. From http://www.asean.org/asean/about-asean/

Brett, J. M., \& Okumura, T. (1998). Inter-and Intercultural negotiation: U.S and Japanese negotiators. Academy of Management Journal, 41(5), 495-510. https://doi.org/10.2307/256938

Earley, P. C. (2002). Redefining interactions across cultures and organization: Moving forward with cultural intelligence. Research in Organizational Behavior, 24, 271-299. https://doi.org/10.1016/S0191-3085(02)24008-3

Earley, P. C., \& Ang, S. (2003). Cultural Intelligence: Individual interactions across cultures. Stanford, California: Stanford University Press.

Fayerweather, J., \& Kapoor, A. (1976). Strategy and negotiations for the international corporation. International Business Review, 18(2), 20-22. https://doi.org/10.1002/tie.5060180210

Gerber, S, B., \& Kristin, V. F. (2005). Using SPSS for Windows: Data analysis and Graphics. New York: Springer, 1-228.

Ghauari, P. N., \& Usunier, J. C. (2003). International Business Negotiations. The Netherlands: Elsevier Ltd (2).

Ghauri, P. N. (1983). Negotiating International Package Deals - Swedish firms and Developing countries. Almquist and Wiksell, Stockholm.

Graham, J. L. (1987). A Theory of Inter-organizational Negotiations. Research in Marketing, Greenwich, CT, JAI Press Inc, 163-183.

Gudykunst, W. B. (1995). Anxiety/Unceirtainty management (AUM) theory: Current status. In R. L. Wiseman (ed), Intercultural communication theory (8-58). Thousand Oaks: Sage.

Hair, J. F. (2010). Multivariate data analysis. NJ, USA: Pearson College Division.

Huber, V. L., \& Neale, M. A. (1987). Effects of self- and competitor goals on performance on an interdependent bargaining task. Journal of Applied Psychology, 72(2), 197-203. https://doi.org/10.1037/0021-9010.72.2.197

Kline, R. B. (2005). Principles and Practice of Structural Equation Modeling (2nd ed.). New York, Guilford.

Lewicki, R. J., Barry, B., Saunders, D., \& Minton, J. (2003). Negotiation. McGraw Hill, New York.

Liu, L. A., Chua, C. H., \& Stahl, G. (2010). Quality of Communication Experience: Definition, Measurement, and Implications for Intercultural Negotiations. Journal of Applied Psychology, 95(3), 469-487. https://doi.org/10.1037/a0019094

Liu, W., \& Liu, A. L. (2006). Cultural Intelligence in International Business Negotiation. SSRN Electronic Journal, 8-18. https://doi.org/10.2139/ssrn.905460

Locke, E. A., Frederick, E., Lee, C., \& Bobko, P. (1984). Effect of Self-efficacy, goals, and task strategies on task 
performance. Journal of Applied Psychology, 69, 241-251. https://doi.org/10.1037/0021-9010.69.2.241

McCall, J. B., \& Warrington, M. B. (1989). Marketing by Agreement: A Cross-Cultural Approach to Business Negotiation. John Wiley and Sons Ltd, Chichester.

Miles, E. W., \& Maurer, T. J. (2012). Advancing validity of self-efficacy in negotiation through focusing at the domain level. Journal of Occupational and Organizational Psychology, 85, 23-41. https://doi.org/10.1348/096317910X531744

Nguyen, K. Y., Dyne, L. A., \& Ang, S. (2009). From Experience to Experimential Learning: Cultural Intelligence as a Learning Capability for Global Leader Development. Academy of Management of Management Learning and Education, 1-40.

O'connor, K. M., \& Arnold, J. A. (2001). Distributive spirals: negotiation impasses and the moderating role of disputant self-efficacy. Organizational Behavior and Human Decision Processes, 84(1), 148-176. https://doi.org/10.1006/obhd.2000.2923

Oolders, T., Chernyshenko, S. O., \& Stark, S. (2008). Cultural Intelligence as a Mediator of Relationships between Openness to Experience and Adaptive Performance. In S. Ang and L. V. Dyne (eds), Handbook of Cultural Intelligence: Theory, Measurement and Applications. London and New York: Routledge.

Preacher, K. J., \& Hayes, A. F. (2008). Asymptotic and resampling strategies for assessing and comparing indirect effects in multiple mediator models. Behavior research methods, 40(3), 879-891. https://doi.org/10.3758/BRM.40.3.879

Pruitt, D. G. (1981). Kissinger as a traditional mediator with power. In J. Z. Rubin (ed), Dynamics of third party intervention: Interdisciplinary perspectives on international conflict. New York: Praeger, 136-147.

Stephan, W. G., \& Stephan, C. (1995). Intergroup anxiety. Journal of Social Issues, 41, 157-176. https://doi.org/10.1111/j.1540-4560.1985.tb01134.x

Thompson, L. (1990). The Influence of Experience on Negotiation Performance. Journal of Experimental Social Psychology, 26, 528-544. https://doi.org/10.1016/0022-1031(90)90054-P

Tung, R. (1988). Toward a Conceptual Paradigm of International Business Negotiations. In R. Farmer (ed), Advances in International Comparative Management. Greenwich CT, JAI Press Inc, 203-219.

Usunier, J. C. (1996). Cultural Aspects of International Business Negotiations.: Negotiations. Oxford Press.

Weingart, L. R., Bennett, R. J., \& Brett, J. M. (1993). The impact of consideration of issues and motivational orientation on group negotiation process and outcome. Journal of Applied Psychology, 78, 504-517. https://doi.org/10.1037/0021-9010.78.3.504

Weingart, L. R., Thompson, L. L., Bazerman, M. H., \& Carroll, J. S. (1990). Tactical behavior and negotiation outcomes. International Journal of Conflict Management, 1, 7-31. https://doi.org/10.1108/eb022670

Wenzlaff, K. (2008). Youth, Culture, Negotiation and Politics. Asian Europe Journal, 5(4), 573-579. https://doi.org/10.1007/s10308-007-0138-y 
Appendix. Variables and items included in the questionnaire

\begin{tabular}{|c|c|c|c|}
\hline Variables & Items & Measurements & Sources \\
\hline \multirow{6}{*}{$\begin{array}{l}\text { Quality of Communication } \\
\text { Experience (CQE) }\end{array}$} & CQE1 & I understood what the other side was saying & \multirow{6}{*}{ Liu et al., 2010} \\
\hline & CQE2 & $\begin{array}{l}\text { We clarified the meaning if there was a confusion of the message } \\
\text { exchanged. }\end{array}$ & \\
\hline & CQE3 & $\begin{array}{l}\text { The conversation ran smoothly without any uncomfortable silent } \\
\text { moment or I did not notice any uncomfortable silent moments. }\end{array}$ & \\
\hline & CQE4 & $\begin{array}{l}\text { When the other side raised questions or concerns, I tried to address } \\
\text { them immediately. }\end{array}$ & \\
\hline & CQE5 & I felt comfortable interacting with the other side & \\
\hline & CQE6 & The other side seemed comfortable talking with me. & \\
\hline \multirow{5}{*}{$\begin{array}{l}\text { Negotiation Self-efficacy } \\
\text { (NS) }\end{array}$} & NS1 & I consider it easy to negotiate with foreigner counterpart. & \multirow{5}{*}{$\begin{array}{c}\text { Miles \& } \\
\text { Maurer, } 2012\end{array}$} \\
\hline & NS2 & I can respond to my counterpart easily during negotiation & \\
\hline & NS3 & $\begin{array}{l}\text { I consider that I have the ability to negotiate with foreigner } \\
\text { counterpart. }\end{array}$ & \\
\hline & NS4 & I consider that I can negotiate with foreigner counterpart fluently. & \\
\hline & NS5 & Overall I have confidence in negotiating with foreigner counterpart. & \\
\hline \multirow{16}{*}{ Cultural Intelligence (CQ) } & CQ1 & $\begin{array}{l}\text { I am conscious of the cultural knowledge I use when interacting } \\
\text { with counterpart from different cultural backgrounds. }\end{array}$ & \multirow{16}{*}{$\begin{array}{l}\text { Ward \& Fischer, } \\
2008\end{array}$} \\
\hline & CQ2 & $\begin{array}{l}\text { I am conscious of the cultural knowledge I apply to cross-cultural } \\
\text { interactions. }\end{array}$ & \\
\hline & CQ3 & $\begin{array}{l}\text { I adjust my cultural knowledge as I interact with counterpart from a } \\
\text { cultural unfamiliar to me. }\end{array}$ & \\
\hline & CQ4 & $\begin{array}{l}\text { I check the accuracy of my cultural knowledge as I interact with } \\
\text { counterpart from difference culture. }\end{array}$ & \\
\hline & CQ5 & I know the legal and economic systems of counterpart cultures. & \\
\hline & CQ6 & I know the religious beliefs of counterpart culture. & \\
\hline & CQ7 & I know the rules (e.g., vocabulary, grammar) of other languages & \\
\hline & CQ8 & $\begin{array}{l}\text { I know the rules for expressing non-verbal behaviors in counterpart } \\
\text { culture. }\end{array}$ & \\
\hline & CQ9 & I enjoy interacting with counterpart from different cultures. & \\
\hline & CQ10 & I enjoy living in cultures that are unfamiliar to me. & \\
\hline & CQ11 & $\begin{array}{l}\text { I am confident that I can socialize with locals in a culture that is } \\
\text { unfamiliar to me. }\end{array}$ & \\
\hline & CQ12 & $\begin{array}{l}\text { I am sure I can deal with the stresses of adjusting to a cu lture that is } \\
\text { new to me. }\end{array}$ & \\
\hline & CQ13 & $\begin{array}{l}\text { I change my verbal behavior (e.g., accent, tone) when a } \\
\text { cross-cultural interaction requires it. }\end{array}$ & \\
\hline & CQ14 & $\begin{array}{l}\text { I change my non-verbal behavior when a cross-cultural interaction } \\
\text { requires it. }\end{array}$ & \\
\hline & CQ15 & $\begin{array}{l}\text { I vary the rate of my speaking when a cross-cultural situation } \\
\text { requires it. }\end{array}$ & \\
\hline & CQ16 & $\begin{array}{l}\text { I alter my facial expressions when a cross-cultural interaction } \\
\text { requires it. }\end{array}$ & \\
\hline \multirow{9}{*}{$\begin{array}{l}\text { Performance of International } \\
\text { Bussiness Negotiation }(\mathrm{P})\end{array}$} & $\mathrm{P} 1$ & Future agreements between parties are likely to happen. & \multirow{9}{*}{ Usunier, 1996} \\
\hline & $\mathrm{P} 2$ & Potential future relationship between parties is strengthened. & \\
\hline & P3 & $\begin{array}{l}\text { The joint mutual gains are shared between parties after the } \\
\text { negotiation. }\end{array}$ & \\
\hline & P4 & $\begin{array}{l}\text { Parties obtain the efficiency of the result after the negotiation: the } \\
\text { party gains cost-effective outcomes. }\end{array}$ & \\
\hline & P5 & $\begin{array}{l}\text { The outcome is parity after the negotiation: each party obtains equal } \\
\text { gains }(50-50) \text {. }\end{array}$ & \\
\hline & P6 & Parties are very satisfaction with the result. & \\
\hline & P7 & $\begin{array}{l}\text { Parties complete transaction very smoothly (i.e. an agreement is } \\
\text { signed). }\end{array}$ & \\
\hline & P8 & $\begin{array}{l}\text { Level of performance afterward: an achievement of work under the } \\
\text { agreement. }\end{array}$ & \\
\hline & P9 & I obtain the self monetary gain after the negotiation & \\
\hline
\end{tabular}

\section{Copyrights}

Copyright for this article is retained by the author(s), with first publication rights granted to the journal.

This is an open-access article distributed under the terms and conditions of the Creative Commons Attribution license (http://creativecommons.org/licenses/by/4.0/). 